\title{
Determination of Formation Strata and Groundwater Potential in Sapele Metropolis and Environ
}

\section{${ }^{* 1}$ OKOLIE, EC; ${ }^{2}$ OSEMEIKHIAN, JEA; ${ }^{2}$ UJUANBI, O}

\author{
${ }^{I}$ Department of Physics, Delta state university Abraka \\ ${ }^{2}$ Department of Physics, Ambrose Alli University Ekpoma
}

\begin{abstract}
This study was carried out in Sapele, Jesse and Oghara, Delta state to determine the groundwater potential by correlating results of seismic refraction survey and those of electrical resistivity studies. Fifteen vertical electrical sounding (VES) locations were sounded and nine seismic stations were shot to complement the study. The seismic results show that the area has generally three or four layer formations. The thin weathering layer with thickness of $1.0-3.5 \mathrm{~m}$ has velocity range of $250-350 \mathrm{~m} / \mathrm{s}$. while the velocities of second and third layers range from $900-1400 \mathrm{~m} / \mathrm{s}$ to consolidated zone. The analysis of the VES data delineated 4 to 5 layers with HK and AKA curves types mainly and showed that the formation of the area is basically conducting which suggests the existence of heavy clay or clayey sand formations. Although the numbers of layers delineated differ, both methods indicate that viable aquifer at Sapele and Jesse is generally within $25 \mathrm{~m}$ although false and contaminated aquifer may be intercepted at $10-15 \mathrm{~m}$. On the contrary, Oghara is more of sandy formation with aquifer above $35 \mathrm{~m}$. @JASEM
\end{abstract}

Some tributaries to the Atlantic Ocean flank Sapele. As a result, residence of Sapele metropolis and environ had depended on the nearby flowing rivers for their domestic use for several years. However, with the increasing activities of the oil sector and allied companies, the flowing waters are now obviously unfit for use. During the rains a large part of it is flooded and filthy as its formations do not allow easy peculation of water. This also renders the numerous hand dug shallow wells useless. The resultant effect is that although there seemed to be water everywhere, there is no potable water for the residence. The only reliable alternative source in this terrain are hand-dug dip wells. This can only be achieved through correct detection and siting of potable ground water. With increased awareness and understanding of personal and domestic hygiene, the ever growing population of these communities are in dare need of long term reliable water source. The availability of potable water is not a certainty in Sapele metropolis because of terrain problem and associated contamination. Geophysical investigation is therefore necessary to determine adequate siting of boreholes. The resistivity property of the earth is usually utilized in groundwater studies. However, it is necessary to carry out geophysical studies using more than one method to effectively delineate formation profile to groundwater depth. It is therefore necessary to determine empirically, the formation strata and ground water distribution in the metropolis and environ for effective siting of viable wells. This is the thrust of the work. Geophysical studies were therefore, carried out using Vertical Electrical Sounding (VES) method and complimented with Seismic refraction soundings of selected sites in Sapele, Jesse and Oghara. The results of the study were then correlated with existing borehole data.

Geology of the area: The area of study is within the Niger Delta basin. It possesses the characteristic blend of the Sambreiro deltaic features and Benin formation. It lies within latitude $6^{\circ} \mathrm{N}$ and longitude $5.30^{\circ} \mathrm{E}$ (Fig 1). It is basically marked with thick vegetation as it is flanked by the Warri and Ethiope rivers which are major tributaries to River Focardos. Moreover, its geographical position is characterised with considerable rain fall each year. The top soil ranges from sandy clay to clayey which makes peculation of water difficult during the rains. This explains the existence of numerous hand dug wells in the locality. 


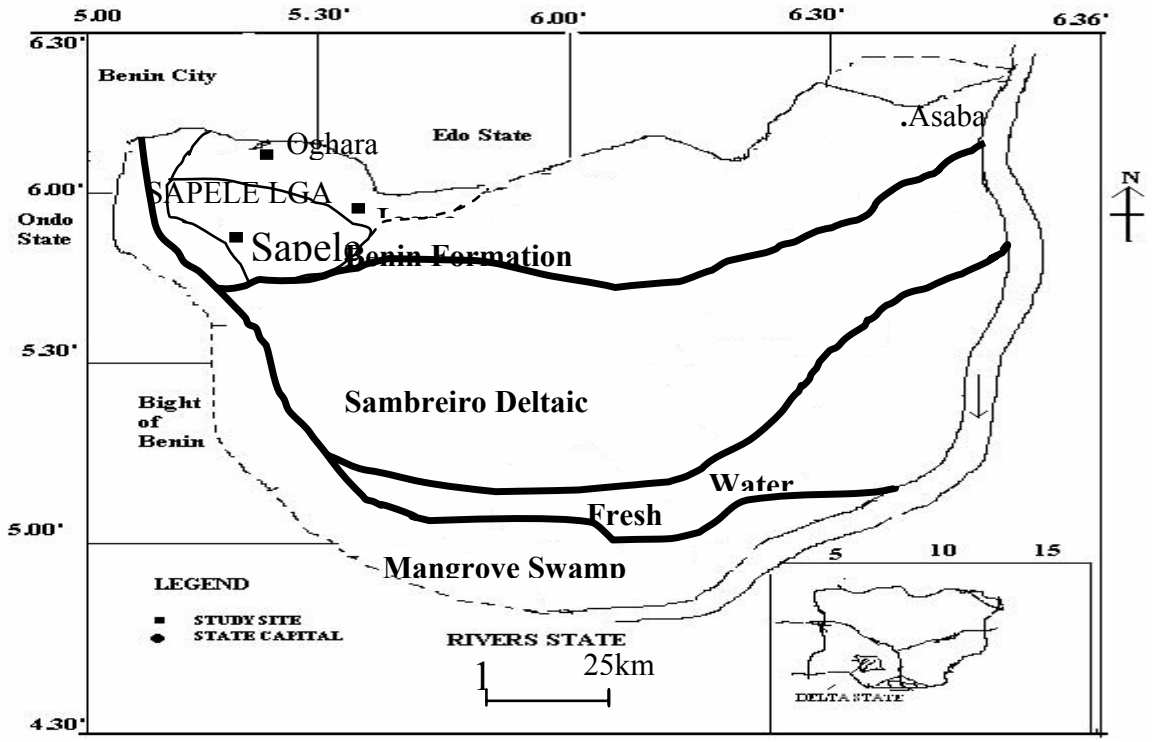

Fig. 1: Base map of Study Area

\section{MATERIALS AND METHOD}

Two principal prospecting approaches were used (a) the Schlumberger array for Vertical Electrical Sounding (VES) study and (b) the Seismic refraction method.

(a) Fifteen carefully selected sites/stations in the study area were mapped out and utilized for vertical electrical sounding using Schlumberger array. A sensitive ABEM 300B Signal Averaging System terrameter powered by a $12.5 \mathrm{DC}$ cadmium Indium battery was used to send current down into the earth through the outer electrodes. A maximum current electrode separation of $928 \mathrm{~m}$ and potential electrode separation up to $30 \mathrm{~m}$ were utilized for most sites to ensure that useful Vertical Electrical Soundings were made in each site. The current and potential pairs of electrodes have a common midpoint $\mathrm{O}$, but the distance between adjacent electrodes differs (Mamah and Ekine 1989) (Fig 2). To obtain the first reading each of the two current electrodes was $1.00 \mathrm{~m}$ away on either side from the station but for all other subsequent readings, the current electrode position from the station was increased by a $\sqrt{2}$ after each reading. On the other hand, each potential electrode was initialled at $0.5 \mathrm{~m}$ on either side of the station but moved only when necessary as required by the array (Osemeikhian and Asokhia 1994). The terrameter used was capable of resolving the current and established potential to display the formation resistance digitally from which the apparent resistivities were calculated using the relevant geometric factor for the array Okwueze, (1996

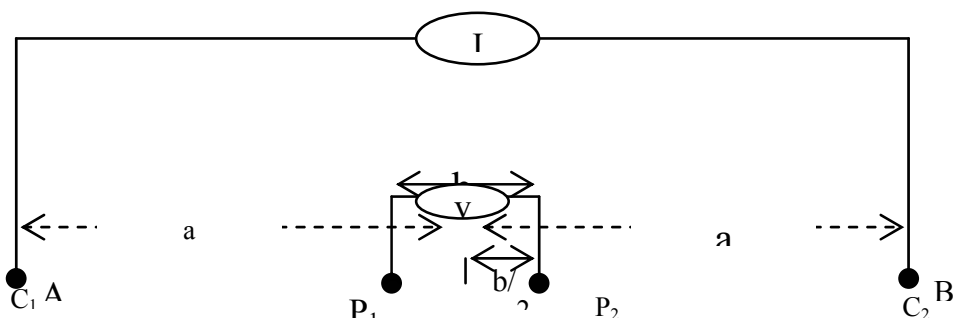

Fig. 2: Schlumberger field Electrode arrangement

n figure (2), the distance between the current electrode and station midpoint, " $b$ " is the distance between potential electrodes and " $2 \mathrm{a}$ " is the current electrode separation. From theory, the potential difference "dV" between the two potential electrodes is 


$$
\begin{aligned}
& d V=V_{P 1}-V_{P 2}=\rho \frac{I}{2 \pi}\left\{\frac{1}{a-b / 2}-\frac{2}{a+b / 2}+\frac{1}{a-\frac{b}{2}}\right\} \\
& =\frac{\ell_{I}}{2 \pi}\left(\frac{8 b}{4 a^{2}-b^{2}}\right) \quad(1 b)
\end{aligned}
$$

so that

$d V=\frac{\rho I b}{\pi a^{2}}$

and $\rho_{a s}=\frac{\pi a^{2}}{b} \frac{d V}{I}=\frac{\pi a^{2}}{b} R$.

where as $\bar{\rho}^{\text {apparent resisitivity for Schlumberger array }}$

and geometric factor, $\mathrm{K}_{\mathrm{s}}$ is given by $\mathrm{K}_{\mathrm{s}}=\frac{2 \pi}{8 b}\left(4 a^{2}-b^{2}\right)$

(b) The seismic refraction survey was done using a 12 - channel Seismograph OYO MESEIS 160mx. The geophones were linearly spread out on the surface of a randomly selected site and shots were taken with a geophone configuration $3,2,2,3,3,5$, $6,5,3,3,2,2$ in metres to make a total spread of 39 metres. A 3 - metre offset from the spread was maintained between the shot point [sensor] and the first geophone to minimize errors and eliminate distortions. Another offset of $1.5 \mathrm{~m}$ perpendicular to spread was also maintained for each geophone position. This horizontal profile array ensured that both forward and reverse shots were refracted back to the geophones with minimum distortion. When the shot was taken, seismic refraction pulses received by each geophone were displayed on the screen of the seismograph and printed out instantly for analyses, Asokhia (1995).

In this case, the wave-fronts are associated with energy travelling directly through an upper layer to detector at $\mathrm{G}$, a distance $\mathrm{X}$ from the source, and energy critically refracted in a lower layer from a seismic source at $\mathrm{S}$, to detector at $\mathrm{G}$ as shown in Fig. 3.

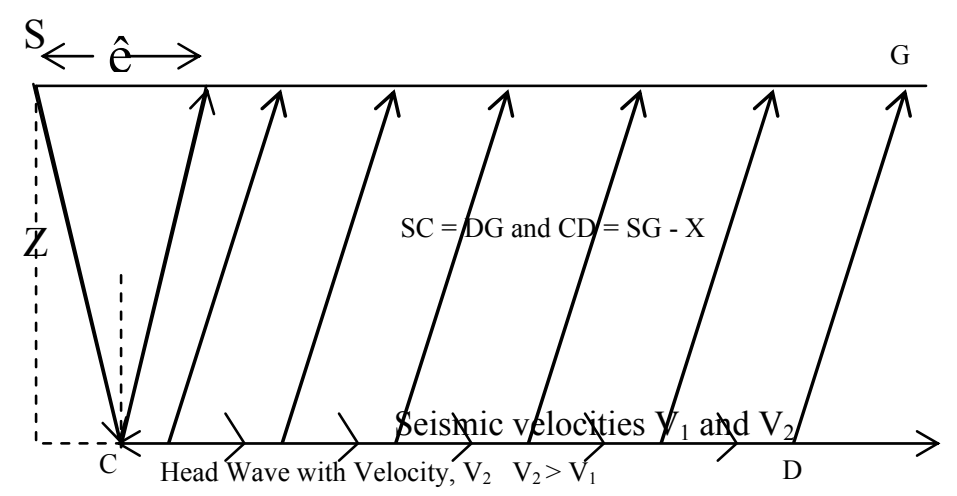

Fig 3: Travel time for direct, reflected and refracted rays between two layers

The layer velocities are $V_{1}$ and $V_{2},\left(V_{2}>V_{1}\right)$ and the refracting interface is at a depth $Z$ (Fig. 3). The direct rays travel horizontally through the top of the upper layer from $S$ to $G$ with velocity $V_{1}$ while the doubly refracted ray travels through path $\mathrm{SC}$ to $\mathrm{D}$ with greater velocity $\mathrm{V}_{2}$ and then to geophone (detector) "G".
The sonic travel time of the wave through path SCDG by definition is,

$$
\mathrm{t}=\frac{2 S C}{V_{1}}+\frac{C D}{V_{2}}
$$




$$
\begin{aligned}
& \mathrm{t}=\frac{2 Z}{V_{1} \cos i_{c}} \frac{2 Z}{V_{2}}+\frac{X-2 Z \tan i_{c}}{V_{2}} \\
& \text { (5a) }
\end{aligned}
$$

and the travel time becomes

$$
\mathrm{t}=\frac{X i}{v_{2}}+2 Z \frac{\operatorname{Cos}_{i}}{v_{i}}
$$

A plot of $t$ against $x$ gives a straight line (linear) graph with slope $={ }^{1} / \mathrm{V}_{2}$ and initial time which is the intercept $=2 Z \frac{\operatorname{Cos}_{i}}{v_{i}}$

Hence, Initial time, $\mathrm{t}_{1}=2 Z \frac{\operatorname{Cos}_{i}}{v_{i}} \mathrm{~V}_{1}$

Hence, $\mathrm{t}_{1}=\frac{2 \mathrm{Z} \sqrt{V_{2}^{2}-V_{1}^{2}}}{V_{1} V_{2}}$

where, $\operatorname{Cos} \underline{\underline{i}}_{\underline{\mathrm{c}}}=\sqrt{\frac{V_{2}^{2}-V_{1}^{2}}{V_{2}}}$

and, the thickness of the interface is,

$$
\mathrm{z}=1 / 2 \frac{V_{1} V_{2} t_{1}}{\sqrt{V_{2}^{2}-V_{1}^{2}}} .
$$

Lowrie, (1997), Osemeikhian, and Asokhia, (1994)

Analysis of Field Data: (a) Data obtained from VES (Table1) were plotted in a bi - log graph from which qualitative analysis was made and the resistivity and thickness of the first layer of each site as well as the resistivity replacements and thickness replacements for other layers were deduced by curve matching technique Zohdy, et al (1974). These were then used to calculate for the apparent resistivities and thicknesses of other layers and subsequently iterated to obtain the final smoothed values Sigmund and Schwarz (1998) (Table 2).
(b)The seismograph printouts of each site was used to determine the first arrival of signal at each geophone which were used to plot a time - distance graph (Fig. 4) from which the velocities of seismic waves in the formations and the thicknesses of the various transmission media were obtained (Okwueze, 1988). The various layer thicknesses for the sites were determined using equations $5-8$.

\section{RESULTS}

(a) The analysis of VES data delineated 4 to 5 layers with HK and AKA curves types mainly and shows that the formations of the area are basically conducting. The resistivity ranges from $10 \Omega \mathrm{m}$ to 120 $\Omega \mathrm{m}$ in Sapele , $50 \Omega \mathrm{m}$ to $430 \Omega \mathrm{m}$ in Jesse and 80 $\Omega \mathrm{m}$ to $190 \Omega \mathrm{m}$ in Oghara. The geoelectric section of the area shows that Sapele is indicative of higher conductivity than Jesse and Oghara (Fig. 3). This confirms that Sapele is predominantly clay while Jesse is mainly sandy clay to Medium grain sand. The analysis also, indicates that formation in Oghara is a blend of fine sand and silt to far depth. However, sites closed to the river bank at Oghara show evidence of clayey formation. This gives an empirical explanation to the difficulty in peculation of water into the soil and the existence of numerous hand dug wells in Sapele metropolis while at Jesse and Oghara, a distance of about 10 and $15 \mathrm{~km}$ respectively, from Sapele, hand dug well is non existent and there is no case of flooding. The analysis and results deduced conform very well to direct borehole log of selected sites in the area.

(b)The complementary results from Seismic refraction studies are indicative of three velocity layers with the velocity of the first layer between 250 and $295 \mathrm{~m} / \mathrm{s}$ and thickness of 0.20 to $0.40 \mathrm{~m}$, while the second layer velocity is between 790 and $100 \mathrm{~m} / \mathrm{s}$ with thickness range of 3.0 to $8.0 \mathrm{~m}$. The third layer velocity ranges from $1400-1600 \mathrm{~m} / \mathrm{s}$ which is evident of water - bearing medium (Fig 4). The analyses from these two approaches were then used to develop a geometric section of the study area (Fig. $5)$.

Table 1: Apparent Resistivity Values (Field Data) from Schlumberger Soundings

\begin{tabular}{ccccccc}
\hline $\begin{array}{c}\mathrm{MN} / 2 \\
(\mathrm{~m}) \\
(\text { Sample })\end{array}$ & $\begin{array}{c}\mathrm{AB} / 2 \\
(\mathrm{~m})\end{array}$ & $\begin{array}{c}\text { Geometric } \\
\text { Factor } \\
\left(\mathrm{K}_{\mathrm{s}}\right) \\
(\text { Sample) }\end{array}$ & $\begin{array}{l}\text { Smoothed } \\
\text { Apparent } \\
\text { Resistivity } \\
(\Omega \mathrm{m}) \\
(\text { Sapele) } \\
(\text { Okpe Rd) }\end{array}$ & $\begin{array}{l}\text { Smoothed } \\
\text { Apparent } \\
\text { Resistivity } \\
(\Omega \mathrm{m}) \\
(\text { Oghorode Rd) }\end{array}$ & $\begin{array}{l}\text { Smoothed } \\
\text { Apparent } \\
\text { Resistivity } \\
(\Omega \mathrm{m}) \\
(\mathrm{Jess})\end{array}$ & $\begin{array}{l}\text { Smoothed } \\
\text { Apparent } \\
\text { Resistivity } \\
(\Omega \mathrm{m}) \\
(\text { Oghara })\end{array}$ \\
\hline 0.2 & 1.00 & 7.5 & 21 & 07 & 50 & 51 \\
& 1.47 & 16.7 & 60 & 18 & 63. & 56 \\
& 2.15 & 36.0 & 92 & 12 & 75 & 58 \\
& 3.16 & 78.1 & 120 & 20 & 103 & 67 \\
& 4.64 & $168.8 / 32.3$ & 140 & 33 & 120 & 47 \\
\hline
\end{tabular}

OKOLIE, EC; OSEMEIKHIAN, JEA; UJUANBI, O 


\begin{tabular}{cllcccc}
\hline $0.2 / 1.0$ & 6.81 & 71.3 & 193 & 29 & 110 & 46 \\
& 10.00 & 155.5 & 155 & 43 & 141 & 65 \\
& 14.70 & $337.9 / 108.4$ & 128 & 64 & 127 & 100 \\
$1.0 / 3.0$ & 21.50 & 237 & 172 & 88 & 105 & 138 \\
& 31.60 & 18.1 & 114 & 97 & 165 & 285 \\
& 46.40 & $1122.6 / 410.2$ & 120 & 55 & 320 & 584 \\
$3.0 / 8.0$ & 68.10 & 98.0 & 129 & 56 & 452 & 321 \\
& 100.00 & $950.9 /$ & 138 & 24 & 350 & 350 \\
$10.0 / 30$ & 147.00 & $4229 / 2096.3$ & 121 & 11 & 394 & 366 \\
$30 / 50$ & 215.00 & $513.0 / 1374$ & 105 & 23 & 310 & 430 \\
& 316.00 & $179 / 3058.8$ & 86 & 49 & 276 & 325 \\
& 464.00 & 6685 & 100 & \multicolumn{2}{c}{ RMS Error $\%=4.20-4.60$} & 187 \\
\hline
\end{tabular}

TABLE 2: Summary of Analysis of Data from VES Studies

\begin{tabular}{ccccccccccccc}
\hline Station & $(\Omega \mathrm{m})$ & $(\Omega \mathrm{m})$ & $(\Omega \mathrm{m})$ & $(\Omega \mathrm{m})$ & $(\Omega \mathrm{m})$ & $(\Omega \mathrm{m})$ & $\mathrm{h}_{1}(\mathrm{~m})$ & $\mathrm{h}_{2}(\mathrm{~m})$ & $\mathrm{h}_{3}(\mathrm{~m})$ & $\mathrm{h}_{4}(\mathrm{~m})$ & $\mathrm{h}_{5}(\mathrm{~m})$ & $\mathrm{h}_{6}(\mathrm{~m})$ \\
\hline Sapele $(\mathrm{Og})$ & 08 & 15 & 94 & 91 & 72 & 23 & 1.0 & 0.8 & 3.15 & 4.6 & 5.1 & $\infty$ \\
Sapele $(\mathrm{Ok})$ & 20 & 65 & 85 & 120 & 78 & & 1.0 & 2.5 & 5.2 & 9.0 & $\infty$ & $\infty$ \\
Jesse & 50 & 41 & 436 & 240 & 150 & & 1.2 & 2.4 & 4.9 & 3.6 & $\infty$ & 10.5 \\
Oghara & 60 & 150 & 90 & 190 & 80 & & 1.4 & 5.2 & 3.1 & $\infty$ & 10.5 \\
\hline
\end{tabular}

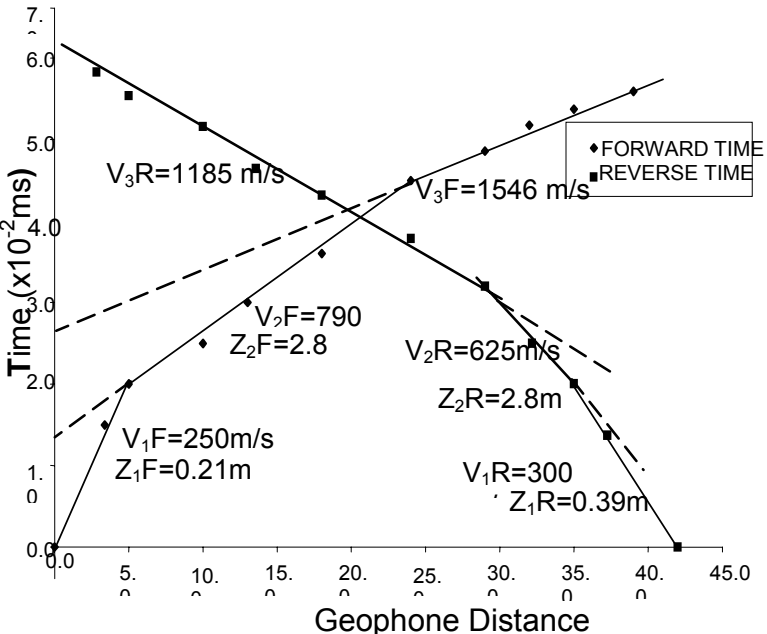

Fig. 4a: Plot of Seismic Survey Data for Sapele Metropolis and Jesse

Conclusion: In conclusion, the formation strata of Sapele and near by towns have been effectively deduced using VES and complimented by Seismic data. Although the numbers of layers delineated by both methods differ, they indicate that viable aquifer at Sapele and Jesse is generally within $20-25 \mathrm{~m}$ but at Oghara, it is up to $40 \mathrm{~m}$. False and contaminated aquifer may be intercepted at $10-15 \mathrm{~m}$ at Sapele. Also, soil formations in Sapele are predominantly

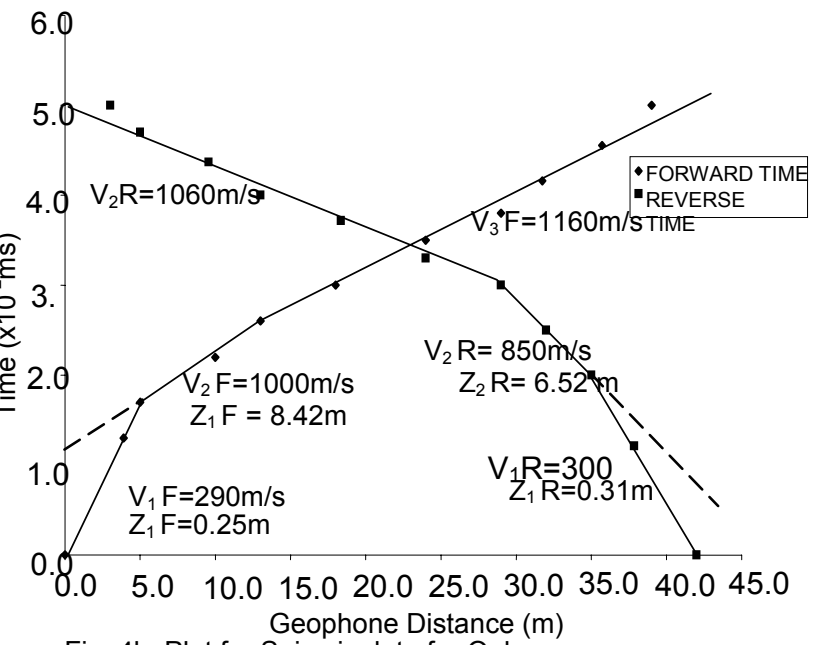

Fig. 4b: Plot for Seismic data for Oghara

clay while those in neighbouring towns, Jesse and Oghara, are found to be smooth sand or sandy clay to medium grain sand which posses less clay. Thus, Sapele is a zone of confined aquifer while Jesse and Oghara are not. It is therefore, obvious that deep wells in Sapele are more likely to be free of contaminations than those in Jesse and Oghara despite the surface water flooding for almost half of the year in most parts of Sapele (Fig 5). 


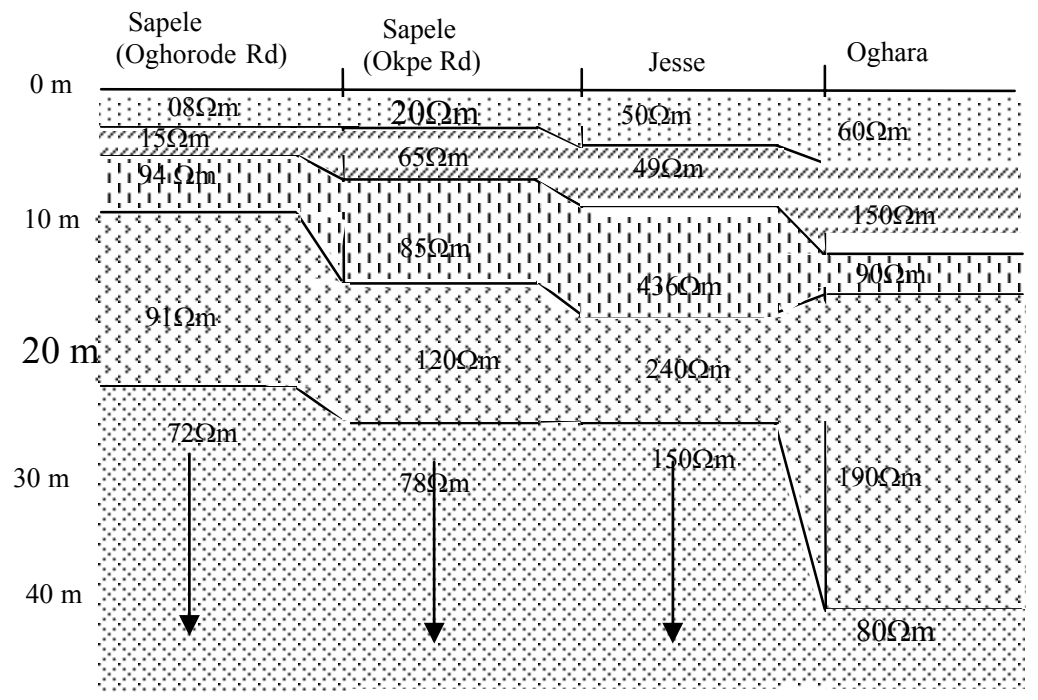

Fig 5: Geoelectric Section for Sapele Metropolis and Environ

\section{REFERENCES}

Asokhia, M.B. (1995). Engineering Geology Samtos Services Ltd Lagos, Nigeria pp 75-82.

Brown R.H, Konoplyansten, A.A. Inesen, J. Kovalesky, V.S (1972). Groundwater studies. A guide for research and practice pp 7- 19 UNESCO Paris

Dobrin, M.D. King, R.F (1965). Introduction to Geophysical prospecting $4^{\text {th }}$ ed. pp 568-581. Mc Graw - Hill New York

Hamill, L. Bell, F.G (1986). Groundwater resource development. Cambridge University Press pp 1158.

Kogbe, C.A (1976). Review of the stratigraphy, sedimentation, and structure of Niger Delta. Geology of Nigeria, pp 260-267. Elizabethan Publishers Co.

Okwueze, E.E (1996). Preliminary findings of the groundwater resource Potentials from a regional geo-electric survey of the Obudu basement area, Nigeria Global Journal of Pure and Applied sciences Vol. 2, No. 2 pg. $201-211$

Okwueze, E. E (1988). Velocity contrast in determining the minimum spread length in seismic refraction prospecting. Journal of mining and geology Vol. 24 Nos. 1 and 2 pp $81-83$

Osemeikhian, J.E.A. Asokhia, M.B (1994). Applied Geophysics. Samtos Services Ltd. Lagos Nigeria

Schwarz, D.S (1998). Applications of geophysical methods to groundwater exploration in the Tolt River basin Washington State. pp 213-217. Pub. Kenmore, Washington

Zohdy, A. A. R. Eaton, G. I. Mabay D. R. (1974). Applications of Surface geophysics to Groundwater investigation. Washington, US Geophysical Survey pp 2401-2543. 